\title{
NMDA Receptor and Nitric Oxide Synthase Activation Regulate Polysialylated Neural Cell Adhesion Molecule Expression in Adult Brainstem Synapses
}

\author{
Farima Bouzioukh, ${ }^{1,2}$ Fabien Tell, ${ }^{1}$ André Jean, ${ }^{1}$ and Geneviève Rougon ${ }^{2}$ \\ ${ }^{1}$ Laboratoire de Neurobiologie des Fonctions Végétatives, Faculté de Saint Jérôme, Centre National de la Recherche \\ Scientifique (CNRS) Formation de Recherche en Évolution 2132-Unité Sous Contrat Institut National de la Recherche \\ Agronomique 1147, 13397 Marseille, Cedex 20, France, and 2Laboratoire de Génétique et Physiologie du \\ Développement, Institut de Biologie du Développement de Marseille, CNRS Unité Mixte de Recherche 6545, Parc \\ Scientifique de Luminy, 13288 Marseille, Cedex 09, France
}

Here we report that synapses in the adult dorsal vagal complex, a gateway for many primary afferent fibers, express a high level of the polysialylated neural cell adhesion molecule (PSANCAM). We show that electrical stimulation of the vagal afferents causes a rapid decrease of PSA-NCAM expression both in vivo and in acute slices. Inhibition of NMDA receptor activity completely prevented the decrease. Blockade of calmodulin activation, neuronal nitric oxide (NO) synthase, or soluble gua- nylyl cyclase and chelation of extracellular NO mimicked this inhibition. Our data provide a mechanistic framework for understanding how activity-linked stimulation of the NMDA-NOcGMP pathway induces rapid changes in PSA-NCAM expression, which may be associated with long-term depression.

Key words: adhesion molecules; NMDAR; NO; plasticity; dorsal vagal complex; PSA-NCAM
The polysialylated form of the neural cell adhesion molecule (PSA-NCAM) has been implicated in many aspects of cell-cell interactions. The carbohydrate polysialic acid (PSA), which is specifically attached to NCAM through a regulated process, can attenuate adhesion forces and modulate cell surface interactions. It thereby orchestrates dynamic changes in the shape and movements of cells and their processes. A convergent set of data suggests that PSA-NCAM supports structural plasticity in the developing and in the adult nervous system (for review, see Rutishauser and Landmesser, 1996; Kiss and Rougon, 1997). In the adult, PSA-NCAM expression is retained only in certain brain areas that undergo structural reorganizations and synaptic plasticity, such as the hypothalamus, the olfactory bulb, and the hippocampus (Seki and Arai, 1993). In the adult hippocampus, selective removal of PSA has been associated with functional modifications because it totally suppresses the induction of longterm potentiation (LTP) or long-term depression (LTD) (Muller et al., 1996). Furthermore, LTP is perturbed in mice lacking NCAM and consequently PSA (Muller et al., 1996; Cremer et al., 1998).

The dorsal vagal complex (DVC) located in the dorsal medulla comprises three structures, namely the nucleus of the solitary tract (NST), the area postrema (AP), and the dorsal motor nucleus of the vagus nerve (DMX). The DVC is a gateway for many primary afferents from cardiovascular, respiratory, gastro-

\footnotetext{
Received Jan. 24, 2001; revised March 26, 2001; accepted April 6, 2001.

This work was supported by institutional grants from CNRS to A.J. and G.R. and by European Community Quality of Life Grant EC QLRT 99-02187 to G.R. F.B. was supported by a student fellowship from Direction Générale des Armées.

Correspondence should be addressed to Geneviève Rougon, Laboratoire de Génétique et Physiologie du Développement, Institut de Biologie du Développement de Marseille, Centre National de la Recherche Scientifique Unité Mixte de Recherche 6545, Parc Scientifique de Luminy, 13288 Marseille, Cedex 09, France. E-mail: rougon@ibdm.univ-mrs.fr

Copyright (c) 2001 Society for Neuroscience $\quad 0270-6474 / 01 / 214721-10 \$ 15.00 / 0$
}

intestinal, and other visceral sensory receptors (Jean, 1991; Barraco, 1994). The central control of autonomic function is far from well understood, but neuronal mechanisms for the processing and integration of visceral afferent signals may possess plastic properties similar to those described in the higher brain regions (Miles, 1986; Glaum and Brooks, 1996; Zhou et al., 1997). Synapses afferent to the DVC exhibit both short- and long-term plasticity. Repetitive stimulation of afferent fibers leads to shortor long-term depression of excitatory synapses while inhibitory inputs are potentiated (Miles, 1986; Glaum and Brooks, 1996; Zhou et al., 1997). In adult animals, the DVC also expresses high levels of neuromodulin [ growth-associated protein-43 (GAP-43)] (Kruger et al., 1993) and PSA-NCAM (Bonfanti et al., 1992) that could subserve structural reorganizations and synaptic plasticity in response to afferent activity. In the present study, we have combined in vivo and slice work to examine how synaptic activity modulates expression of PSA-NCAM.

\section{MATERIALS AND METHODS}

In vitro experiments

Transverse brainstem slices $(300 \mu \mathrm{m})$ from the level of the obex were prepared from 4- to 6-week-old Sprague Dawley rats, as described previously (Vincent and Tell, 1997). Briefly, the animal was craniotomized under pentobarbitone sodium anesthesia; the brainstem and upper cervical spinal cord were removed rapidly and glued to the cutting stage of a vibratome. Throughout the surgical and sectioning procedure, the brainstem was immersed in chilled cutting saline saturated with carbogen $\left(95 \% \mathrm{O}_{2}\right.$ and $5 \% \mathrm{CO}_{2}$ ) and contained (in $\mathrm{mm}$ ): $60 \mathrm{NaCl}, 3 \mathrm{KCl}, 0.5$ $\mathrm{CaCl}_{2}, 28 \mathrm{NaHCO}_{3}, 7 \mathrm{MgCl}_{2}, 1.25 \mathrm{Na}_{2} \mathrm{HPO}_{4}, 5$ D-glucose, 110 sucrose, and $0.6 \mathrm{~L}$-ascorbate. After stabilization at $32^{\circ} \mathrm{C}$ in carbogenated artificial CSF (ACSF) [containing (in mM): $130 \mathrm{NaCl}, 3.3 \mathrm{KCl}, 2.45 \mathrm{CaCl}_{2}, 25.6$ $\mathrm{NaHCO}_{3}, 2.4 \mathrm{MgCl}_{2}, 1.25 \mathrm{KH}_{2} \mathrm{PO}_{4}, 10$ D-glucose, 0.4 L-ascorbate, 2 pyruvate, and 3 myo-inositol], the brainstem slice was transferred to a recording chamber on a microscope stage (Axioskop; Zeiss, Oberkochen, Germany), secured with a nylon mesh, and superfused at a constant rate of $3 \mathrm{ml} / \mathrm{min}$ with carbogenated $\mathrm{ACSF}$ at $32^{\circ} \mathrm{C}$. A bipolar electrode was positioned under visual control onto the solitary tract (ST) 
for electrical stimulation. In all studies, the ST was stimulated with a source of constant current using pulses $500 \mu \mathrm{A}$ intensity and $200 \mu \mathrm{sec}$ duration. In most studies, our protocol was a train of pulses at $30 \mathrm{~Hz}$ (train duration of $5 \mathrm{sec}$; train period of $10 \mathrm{sec}$ ) for 5 , 10, or $15 \mathrm{~min}$. In another series, one to three high-frequency pulse trains $(100 \mathrm{~Hz})$ were applied to the tract. Each train was separated by a $5 \mathrm{~min}$ period. Slices were dissected 5 min after the end of the last train; the two halves of the DVC were separated with microscissors and stored in two different microtubes. Samples were stored at $-80^{\circ} \mathrm{C}$ until processing for immunoblotting. Test stimuli $(100 \mu \mathrm{sec})$ were delivered every $20 \mathrm{sec}$ through bipolar tungsten electrodes placed onto ST, as described previously (Zhou and Poon, 2000). Field potentials (FPs) were recorded using glass microelectrodes $(10-20 \mu \mathrm{m}$ tip diameter). The current intensity of test stimuli $(200-300 \mu \mathrm{A})$ was set to produce $40-50 \%$ of the maximum evoked response. The baseline was recorded for at least $10 \mathrm{~min}$ to ensure the stability of the response. LTD was induced using three highfrequency pulse trains. LTD was always attempted in the presence of 20 $\mu \mathrm{M}$ bicuculline. At the end of experiments, tetrodotoxin (TTX) $(3 \mu \mathrm{M})$ was routinely added into the perfusion saline. Before the analysis, the raw FPs were corrected for by subtracting the electrode artifacts recorded in TTX-containing saline, as described previously (Zhou and Poon, 2000). FPs were typically biphasic with an early and late component corresponding to the presynaptic fiber volley and excitatory postsynaptic response, respectively (Zhou and Poon, 2000). Amplitude of the early phase and the slope of the late phase were measured as an index of the stimulus efficacy on presynaptic fibers and of the postsynaptic responses, respectively.

\section{In vivo experiments}

Rats weighing 200-300 gm were anesthetized with pentobarbitone sodium $(50 \mathrm{mg} / \mathrm{kg}$, i.p.) The trachea and the jugular vein were cannulated. One cervical vagus nerve was dissected free from the surrounding tissues. Bipolar silver electrodes were placed on the intact nerve, secured in the muscles, and isolated with Vaseline. Rectal temperature was maintained between 36 and $38^{\circ} \mathrm{C}$. The nerve was stimulated with a repetitive train at $30 \mathrm{~Hz}$ (train duration of $5 \mathrm{sec}$; train period of $10 \mathrm{sec}$ ) for $15 \mathrm{~min}$. The intensity was set at a level such that breathing was markedly inhibited during the first second of stimulation. Nitroarginine $(100 \mathrm{mg} / \mathrm{kg}$ in normal saline) was injected intraperitoneally $1 \mathrm{hr}$ before surgery. Rats were injected with (+)-5-methyl-10,11-dihydro-5H-dibenzo [a,d] cyclohepten-5,10-imine maleate (MK-801) $(2 \mathrm{mg} / \mathrm{kg})$ intravascularly in normal saline $5 \mathrm{~min}$ before the onset of the stimulation. Control animals received corresponding injections of normal saline. Animals were decapitated at the end of the stimulation period. Brainstem slices were prepared as described above and then rapidly processed for immunoblotting. For immunohistochemistry experiments, rats were perfused through the heart with $4 \%$ paraformaldehyde in phosphate buffer before processing.

\section{Immunohistochemistry}

The brains were immersed in fixative (4\% paraformaldehyde in phosphate buffer; $\left.3-5 \mathrm{hr} ; 4^{\circ} \mathrm{C}\right)$. The fixed tissues were sectioned coronally $(50$ $\mu \mathrm{m}$ thickness) with a vibratome. Free-floating sections were permeabilized in PBS-0.3\% Triton X-100 [15 min at room temperature (RT)] and then incubated $(1 \mathrm{hr})$ with $5 \%$ goat serum in $0.1 \mathrm{M} \mathrm{PBS}, \mathrm{pH}$ 7.4. Tissue sections were treated with primary antibody (overnight at $4^{\circ} \mathrm{C}$ ). After washing, sections were incubated with biotinylated goat anti-mouse antibody (1:200; Jackson ImmunoResearch, West Grove, PA), washed in PBS, and developed using the Vectastain ABC kit and DAB kit (Biosys Inc.). Sections were examined with an Axiophot microscope (Zeiss). Control sections treated with secondary antibodies alone showed no staining.

Frozen section immunohistochemistry. Fixed brains were immersed in PBS containing 30\% sucrose. The brainstems were sectioned coronally (20 $\mu \mathrm{m}$ thickness) using a cryostat. Sections were incubated first with $0.01 \%$ digitonin $(20 \mathrm{~min}$ at $\mathrm{RT})$ and then $(1 \mathrm{hr})$ with $15 \%$ fetal calf serum in $0.1 \mathrm{~m}$ PBS, $\mathrm{pH}$ 7.4. Tissue sections were treated with primary antibody (overnight at $4^{\circ} \mathrm{C}$ ). After washing, sections were incubated with FITCconjugated goat anti-mouse IgM (PSA) or Texas Red-conjugated antimouse IgG [GAP-43, synaptophysin, and glial fibrillary acidic protein (GFAP); 1:4000; Jackson ImmunoResearch) antibodies. In doubleimmunolabeling experiments, the use of only one primary antibody followed by the addition of both anti-mouse IgM FITC-conjugated and anti-mouse IgG Texas Red-conjugated antibodies resulted in only single labeling.

Antibodies. The following antibodies were used: mouse monoclonal
(IgM) anti-PSA antibody [1:2000; (Rougon et al., 1986)], mouse monoclonal (IgG) anti-GAP-43 antibody (1:20,000; Roche Products, Hertforshire, UK), mouse monoclonal (IgG) anti-synaptophysin antibody (1: 200; Roche Products), mouse monoclonal (IgG) anti-GFAP antibody (1:8,000; Sigma, St. Louis, MO), and rabbit anti-NCAM antibody [1:1000 (Rougon and Marshak, 1986)].

Quantitative analysis. PSA immunoreactivity (IR) was quantified using densitometric measurements. Image recording was performed at low magnification using a Zeiss stereomicroscope equipped with a CCD camera. All images were taken with constant field illumination using identical camera settings. For each region of interest, average gray levels were measured using a computer-assisted image analysis system (NIH Image). Confocal images were obtained by using a Zeiss Axiovert microscope $135 \mathrm{M}$ with $63 \times$ oil objective and a Zeiss laser-scanning confocal imaging system (LSM 410).

\section{Protein gel electrophoresis and immunoblots}

Brain tissues were homogenized in $2 \%$ Nonidet P-40 and $0.2 \mathrm{M}$ Tris- $\mathrm{HCl}$ buffer, $\mathrm{pH} 8$, containing protease inhibitors. The homogenates were centrifuged at $50,000 \times g\left(1 \mathrm{hr}\right.$ at $\left.4^{\circ} \mathrm{C}\right)$. The supernatants were collected, and protein concentrations were determined. In some instances, a treatment with endoneuraminidase $\mathrm{N}$ purified in our laboratory $(0.2 \mathrm{U} / \mathrm{mg}$ protein; $1.5 \mathrm{hr}$ at RT) was performed on homogenates in the presence of $2 \%$ Nonidet P-40. The samples were mixed with SDS sample buffer, and equal amounts of proteins were fractionated by electrophoresis in $7.5 \%$ polyacrylamide gels containing SDS. Each sample was run twice to verify the absence of an internal variation in the assay. After transfer onto nitrocellulose, PSA or NCAM were revealed by incubation with anti-PSA mouse IgM monoclonal or anti-NCAM rabbit IgG polyclonal antibodies, followed by rabbit anti-mouse IgM (only for PSA), and horseradish peroxydase-conjugated goat anti-rabbit IgG. IR was detected with a chemiluminescence system. A calibration curve was established using purified recombinant fragment constant-PSA-NCAM (data not shown). Results were quantified by imaging densitometry (Bio Image IQ). The minimum amount of PSA-NCAM detectable in the assay was 5 pmol, and the minimum statistically significant difference between two samples was $5 \%$.

\section{Drugs}

Drugs added to the ACSF were as follows: D-2-amino-phosphonovalerate (APV) $(50 \mu \mathrm{M})$; 6-cyano-7-nitroquinoxaline-2, 3-dione (CNQX) $(20 \mu \mathrm{M})$; NMDA $(50 \mu \mathrm{M}) ; 4,4,5,5$-tetramethylimidazoline-1-oxyl-3-oxide (PTIO) (3 $\mu \mathrm{M})$; 7-nitroindazole monosodium salt $(7-\mathrm{NI})(100 \mu \mathrm{M}) ; \mathrm{N}^{\omega}{ }^{\omega}$-nitro-Larginine (NNA) $(1 \mathrm{mM})$; sodium nitroprusside (SNP) $(100 \mu \mathrm{M}) ; S$-nitroso$N$-acetylpenicillamine (SNAP) (100 $\mu \mathrm{M})$; phenylarsine oxide (PAO) $(50$ $\mu \mathrm{M})$; sucrose $(0.45 \mathrm{M})$; bicuculline $(25 \mu \mathrm{M}) ; 1 \mathrm{H}-[1,2,4]$ oxadiazolo [4,3,-a] quinoxalin-1-one (ODQ) (10 $\mu \mathrm{M})$; and calmidazolium (200 nM).

\section{RESULTS \\ PSA-NCAM and GAP-43 expression in the dorsal vagal complex}

A first set of experiments was performed on tissue sections prepared from rats (Fig. $1 A, B, D$ ). Figure 1 shows strong expression of both PSA (Fig. $1 C$ ) and GAP-43 (Fig. $1 E$ ) in the DVC, in contrast with the neighboring areas, which were negative. At a regional level, staining for the two molecules appeared to be superimposed. Staining was limited to the AP, the medial part of the NST (mNST), and the DMX throughout the rostrocaudal axis. Staining was weak or virtually absent in the other brainstem regions, including the inferior olive, the nucleus ambiguus, and the spinal trigeminal nucleus. Interestingly, staining for GFAP was also stronger in the DVC than in the other parts of the section (Fig. $1 F)$.

Because the punctuate PSA labeling (Fig. $1 G-I$ ) was suggestive of a synaptic or perisynaptic localization, we compared the pattern of PSA IR with that of GAP-43 (Fig. $1 G$ ) and synaptophysin (Fig. $1 H$ ), a marker for presynaptic structures. The vast majority of PSA-positive dots were closely apposed to GAP-43- and synaptophysin-positive dots. To determine whether glial cells also expressed PSA, double-labeling experiments were performed 
A

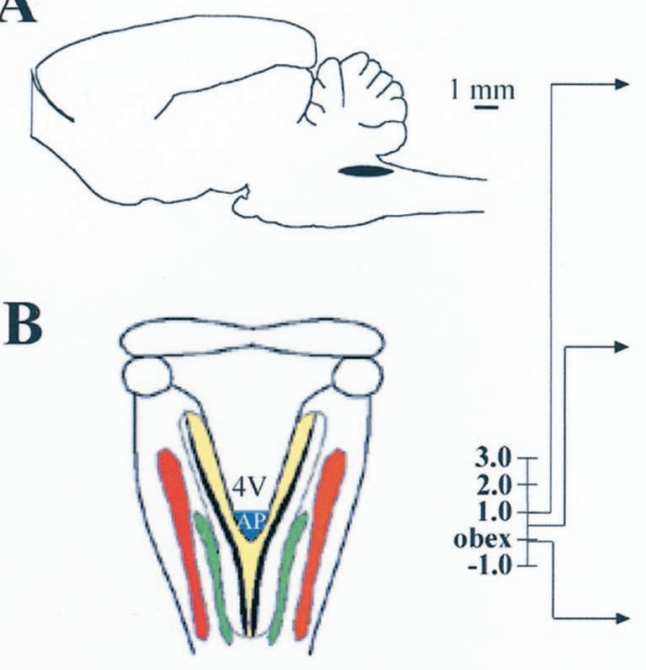

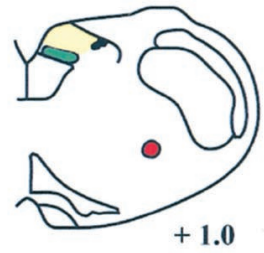
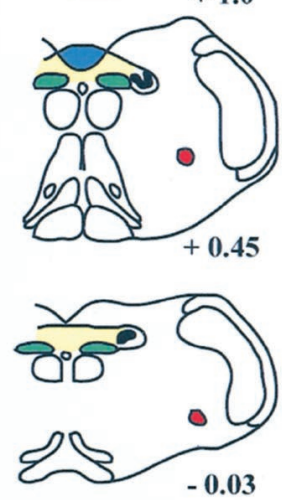
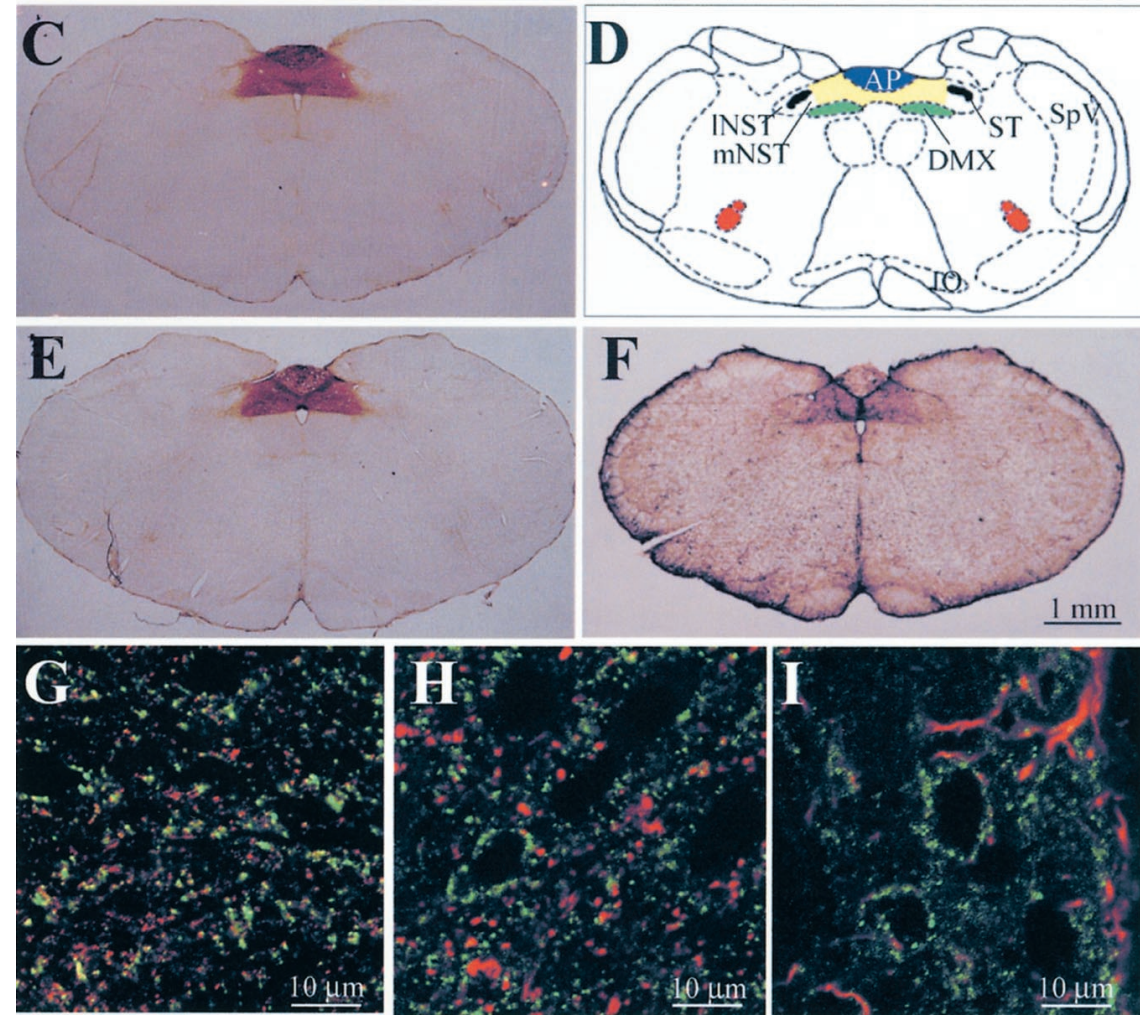

Figure 1. Localization of PSA in the dorsal vagal complex. $A$, Schematic drawing of a sagittal view of the brain showing the localization of the DVC. $B$, Schematic drawing of a dorsal view of the dorsal vagal complex with transverse sections of the brainstem throughout the rostrocaudal axis. The three sections identify the region of the brainstem selected for the quantitative analysis of modulation of PSA expression. $C$, Transverse section of rat caudal medulla showing distribution of PSA immunolabeling. $D$, Schematic transverse section of the brainstem at the intermediate level of the DVC. $E, F, \mathrm{GAP}-43$ and GFAP labelings, respectively. $G$, Double-staining with anti-PSA (green) and anti-GAP-43 (red) antibodies. $H$, Double-staining with anti-PSA (green) and antisynaptophysin (red) antibodies. I, Confocal observation of double staining with anti-PSA (green) and anti-GFAP (red) antibodies. INST, Lateral NST; XII, hypoglossal nucleus; $S p V$, spinal trigeminal nucleus; $N A$, nucleus ambiguus; $I O$, inferior olive. with anti-PSA and anti-GFAP antibodies. Cells positive for GFAP exhibited a network-like organization, whereas PSApositive elements were punctiform, and confocal laser microscopy indicated little if any overlap between GFAP and PSA-NCAM staining (Fig. 1I).

\section{Effects of electrical stimulation on PSA-NCAM expression}

In vivo experiments

In vivo experiments were performed on anesthetized adult rats. Stimulation of the cervical vagus nerve $(30 \mathrm{~Hz}, 15 \mathrm{~min})$ induced a substantial decrease in PSA staining in the DVC on the stimulated side compared with that in the contralateral DVC (Fig. $2 A, B)$. Such differences were not detected in control experiments in which the nerve was not stimulated. Levels of PSA IR under control or stimulated conditions were recorded and quantified in different nuclei of the DVC (Fig. $2 A, B$ ). Vagus nerve stimulation induced a significant decrease in PSA levels in DMX and mNST of the stimulated side compared with their contralateral counterparts, and measurements of PSA IR revealed no significant changes in control experiments (Fig. 2B).

The decrease in PSA staining after electrical stimulation of the vagus nerve could result from either a rapid degradation of the molecule or a change of its subcellular localization, which might modify the access of the epitope to the antibody. To discriminate between these two hypotheses, we measured the amount of PSA IR in detergent-solubilized tissue samples. To this end, the DVC 


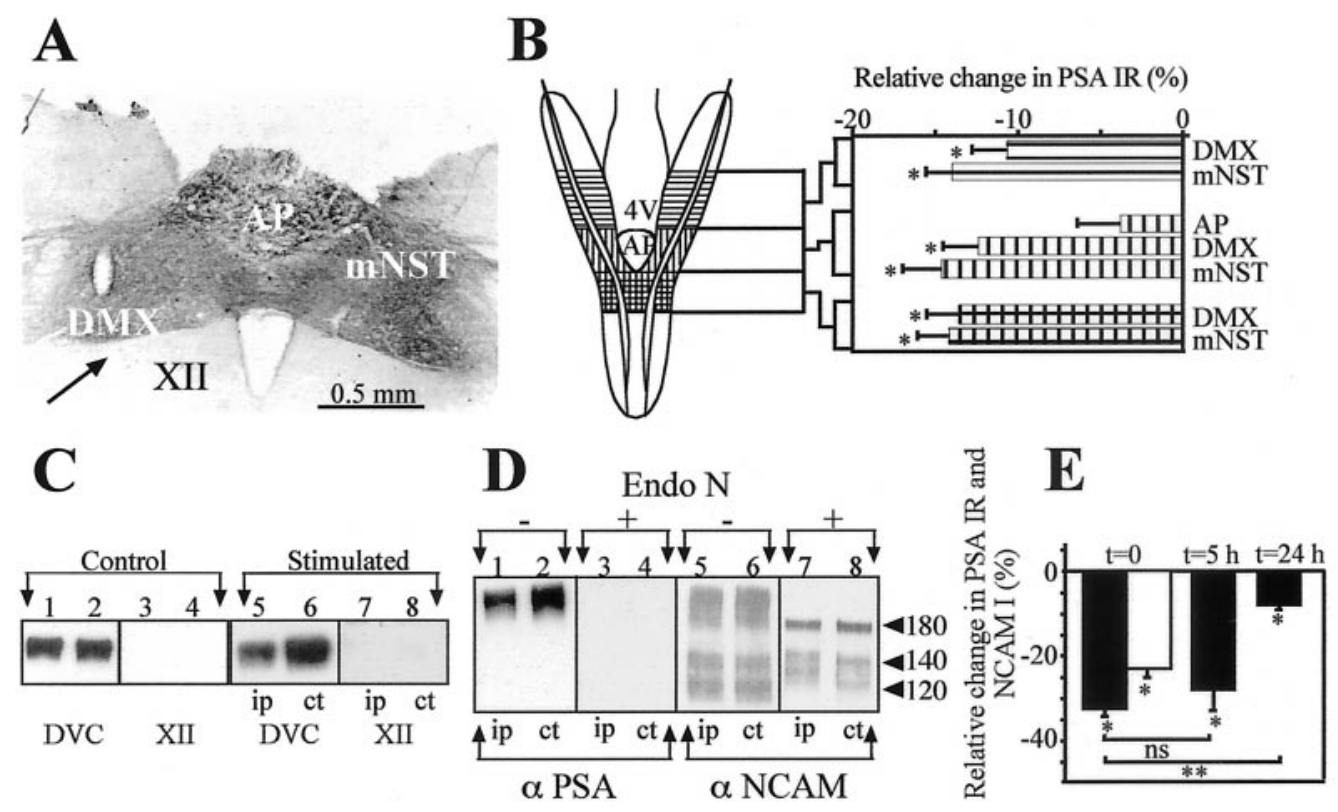

Figure 2. Quantitative analysis of regulation of PSA expression. A, Enlarged section showing PSA immunoreactivity in the DVC after stimulation of the cervical vagus nerve $(15 \mathrm{~min}, 30 \mathrm{~Hz})$. The arrow shows the stimulated side. $B$, Levels of PSA IR were quantified on sections throughout the rostrocaudal axis in three selected structures: the AP, the DMX, and the mNST. The results were analyzed by calculating the ratio of the IR level recorded in the stimulated side over that of the contralateral, nonstimulated side and expressed as a percentage of increase or decrease (ipsilateral side IR/contralateral side IR). $C$, Example of a typical Western blot showing the expression of PSA in control and in stimulated adult rat in the DVC and in the hypoglossal nucleus $(X I I)$. D, Example of a Western blot revealed with anti-PSA (lanes 1-4) and anti-NCAM (lanes 5-8) antibodies in stimulated adult rat. The homogenates were incubated with endoneuraminidase $\mathrm{N}$ (Endo $N$; lanes 3, 4, 7, 8) to remove PSA and visualize NCAM proteins (lanes $7,8)$. E, Quantification of PSA IR (black bars) and NCAM IR (white bar; $n=15$ ) on Western blots after electrical stimulation of the vagus nerve. Rats were stimulated $(15 \mathrm{~min}, 30 \mathrm{~Hz})$ and killed just after the end of the stimulation $(t=0 ; n=21), 5 \mathrm{hr}(t=5 \mathrm{hr} ; n=5)$, or $24 \mathrm{hr}$ later $(t=24 \mathrm{hr} ; n=$ 8 ). Mean \pm SEM of the data. * $p<0.05$; Wilcoxon test; stimulated versus contralateral side for each time considered; $n s$, not significant. ${ }^{* *} p<0.05$; ANOVA; stimulated side at the end of stimulation $(15 \mathrm{~min}, 30 \mathrm{~Hz})$ versus stimulated side 5 and $24 \mathrm{hr}$ after stimulation. ip, Ipsilateral side to the stimulation; $c t$, contralateral side to the stimulation.

was dissected from brainstem slices, at the end of the in vivo stimulation session, and each half was separately collected. Individual DVC halves were then processed for immunoblotting under strictly the same conditions. First, we examined PSA and NCAM IR partitioning in the detergent-soluble (supernatant) and detergent-insoluble (pellet) fractions. Virtually all $(>95 \%)$ of the IR was recovered in the supernatant fraction. We also verified that stimulation did not influence the relative distribution of PSA IR between the two fractions (data not shown). Therefore, for all experiments, data shown are those for the soluble fractions (Fig. $2 C-E)$. As expected, anti-PSA and anti-NCAM antibodies revealed a broad band migrating above $180 \mathrm{kDa}$. Removal of PSA using endoneuraminidase $\mathrm{N}$ (Fig. 2D) showed that PSA was mainly linked to the $180 \mathrm{kDa}$ NCAM isoform. Under both stimulation and control conditions, PSA and NCAM IR were always detected in both halves of the DVC, in contrast with neighboring areas, which were negative for PSA (Fig. 2C) but positive for NCAM (data not shown). We then compared the quantity of PSA IR in both DVCs. In control experiments, when the vagus was not stimulated, PSA IR levels did not differ between the DVCs. In contrast, vagus nerve stimulation $(30 \mathrm{~Hz}, 15 \mathrm{~min})$ induced a strong decrease in the PSA $(\sim 32 \%)$ and NCAM-180 $(\sim 25 \%)$ contents of the ipsilateral DVC compared with the DVC on the nonstimulated side (Fig. 2C-E). These data indicate that vagus nerve stimulation resulted in a rapid decrease in the amount of the $180 \mathrm{kDa}$ PSA-NCAM isoform in the DVC. These low PSA levels persisted for at least $5 \mathrm{hr}$ and then recovered gradually (Fig. 2E).

\section{In vitro experiments}

To determine the molecular mechanisms controlling this rapid modulation of PSA expression, our experimental protocols were adapted for an in vitro preparation. Fresh brainstem slices were kept in a standard perfusion chamber, and fibers afferent to DVC were stimulated with a bipolar electrode placed on the ST (Fig. $3 A$ ). Changes in PSA expression, detected on immunoblots, were expressed as the ratio of ipsilateral/contralateral IR. Controls were performed as for the in vivo experiments (see above).

We verified that mechanical stress from the stimulation electrode did not influence PSA IR levels by showing that placing the electrode onto the ST of one hemi-slice for $15 \mathrm{~min}$ without stimulation caused no differences between the two sides (Fig. $3 B, C)$.

ST stimulation ( $30 \mathrm{~Hz}$ for $15 \mathrm{~min}$ ) in vitro as in vivo induced a decrease in PSA expression (Fig. 3B). The clear downregulation of PSA IR in the ipsilateral side in 31 of 36 slices tested averaged $23 \%$ when ipsilateral and contralateral sides were compared 15 min after the end of the stimulation (Fig. $3 B, C$ ). We then investigated the effects of stimulation duration. For $30 \mathrm{~Hz}$ stimulation, PSA IR decreased as a function of time. The decrease reached $15 \%$ after $5 \mathrm{~min}$ and $20 \%$ after $10 \mathrm{~min}$ of stimulation (Fig. $3 \mathrm{~B}, \mathrm{C}$ ). A single high-frequency $(100 \mathrm{~Hz})$ short-duration $(1 \mathrm{sec})$ stimulation train also induced a significant decrease in PSA IR as soon as 5 min after the end of the stimulation (Fig. 3D). A greater reduction was induced by additional second or third trains applied 5 and $10 \mathrm{~min}$, respectively, after the first. Thus, the decrease in 


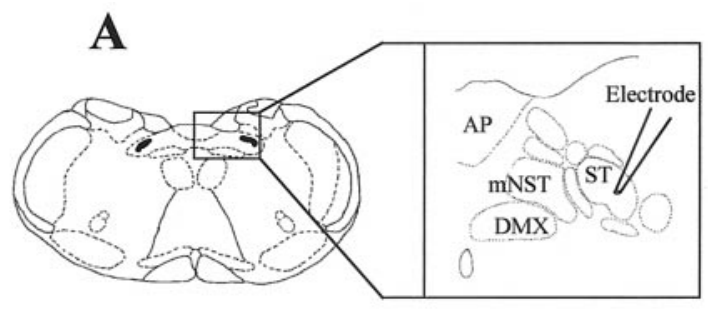

B
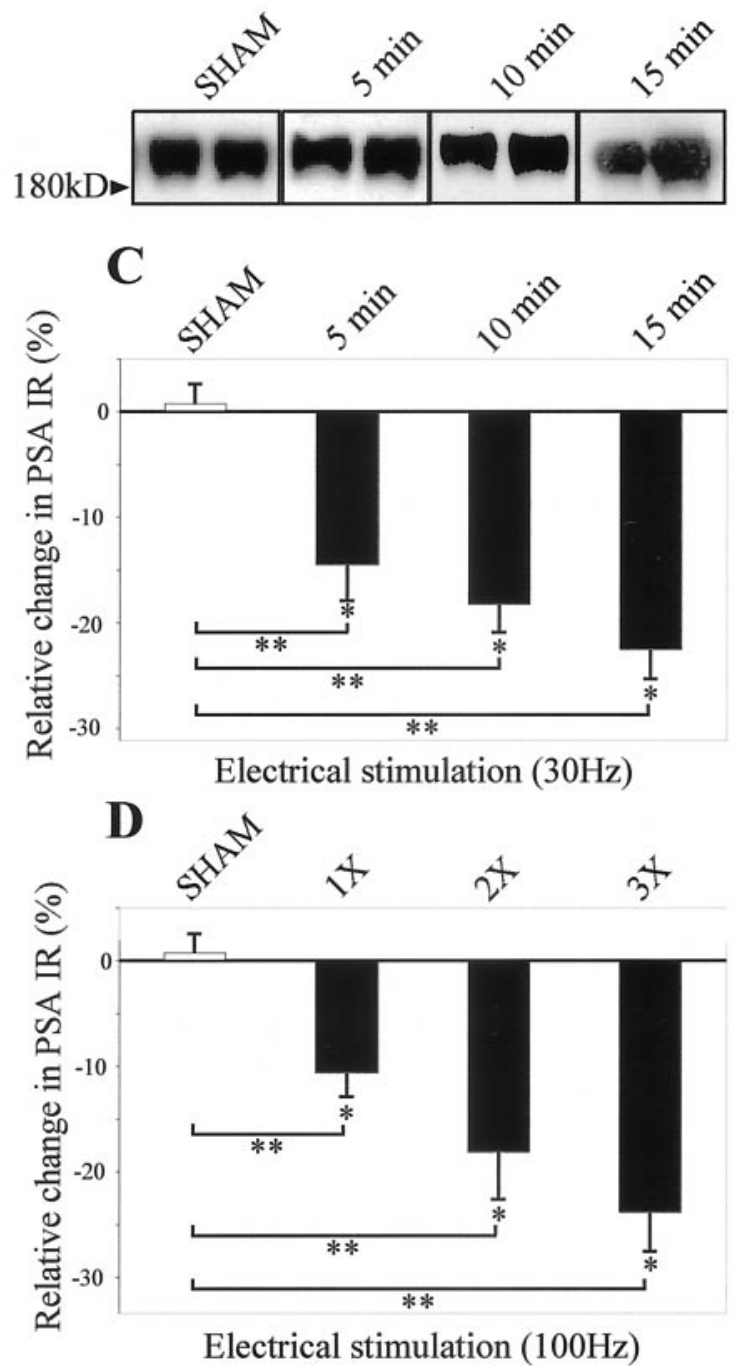

Figure 3. Effects of electrical stimulation of the solitary tract on PSA expression in slices. $A$, Schematic representation of transverse section of brainstem at the level of the AP. The box shows the medial NST and the arrangement of the stimulating electrode. $B$, Typical Western blot showing PSA IR decrease in the ipsilateral side to the stimulation. This decrease was a function of time after the stimulation. $C$, Quantification of PSA on Western blots after electrical stimulation at $30 \mathrm{~Hz}$ during $5(n=5), 10(n=$ $5)$, or $15(n=36) \min (l e f t$ to right). Mean \pm SEM of the data. No statistical significant difference in PSA IRs between the two sides of the DVC was observed for the sham $(n=7) .{ }^{*} p<0.05$; Wilcoxon test; stimulated side versus contralateral side for a given experimental condition. ${ }^{* *} p<0.05$; ANOVA; sham versus stimulated sides for 5, 10, and 15 min of stimulation. $D$, Quantification of PSA IR on Western blots after electrical stimulation of the ST with one $(n=6)$, two $(n=6)$, or three $(n=20)$ high-frequency $(100$ $\mathrm{Hz})$ short-duration $(1 \mathrm{sec})$ stimulation trains applied every 5 min. Mean \pm SEM of the data. * $p<0.05$; Wilcoxon test; stimulated side versus contralateral side for a given condition. ${ }^{* *} p<0.05$; ANOVA; sham versus stimulated sides for one, two, and three stimulation trains.
PSA IR occurs rapidly ( $<5 \mathrm{~min})$ and is sensitive to the number and duration of the stimulation trains.

\section{Activation of NMDA receptors is a prerequisite to PSA decrease}

Peripheral information conveyed by vagal afferent fibers activates predominantly glutamate receptors (Saha et al., 1995; Schaffar et al., 1997). Using a pharmacological approach, we investigated the role of glutamate receptor subtypes in the regulation of PSA expression on brainstem slices. All drugs were tested using the 15 min duration, $30 \mathrm{~Hz}$ frequency stimulation paradigm. Figure $4 A$ shows that coapplication in normal saline of CNQX, an AMPA receptor antagonist, and APV, an NMDA receptor (NMDAR) antagonist, inhibited the stimulation-induced PSA IR decrease; the IR ratio from the two DVCs was similar to that of unstimulated controls. When used separately in normal saline, the drugs yielded similar results. However, in a magnesium-free medium, which removes the magnesium blockade of NMDA receptors at resting potential (Nowak et al., 1984), ST stimulation induced a reduction in PSA IR that was insensitive to CNQX but sensitive to APV. In normal saline, blockade of NMDA receptors by APV also blocked the decrease in PSA IR induced by three trains of stimulation at high frequency (Fig. $4 A$ ).

The involvement of NMDA receptors in the reduction of PSA expression was further confirmed by direct NMDA receptor stimulation. Medullary slices were cut into two halves along the midline. One half was perfused with ACSF containing NMDA and the other with normal saline. The PSA IR of the half superfused with NMDA was always lower than that in the control hemi-slice (Fig. 4A). In similar experiments raising $\mathrm{K}^{+}$concentration to $30 \mathrm{~mm}$ in the ACSF for $7.5 \mathrm{~min}$ also downregulated PSA IR. This effect completely vanished when APV was added to the high-K ${ }^{+}$saline (Fig. $4 B$ ). The effect of ST stimulation on PSA (Fig. $4 B$ ) was not abolished by addition of bicuculline to the perfusing saline, suggesting that $\mathrm{GABA}_{\mathrm{A}}$ receptors do not contribute to PSA regulation.

\section{Nitric oxide-cGMP pathway regulates the expression of PSA-NCAM}

Activation of NMDA receptors may cause nitric oxide (NO) release and cGMP formation (East and Garthwaite, 1991). We therefore tested whether the PSA IR decrease induced by ST stimulation was dependent on the activation of the NO pathway. All drugs were tested as previously with stimuli at $30 \mathrm{~Hz}$ applied for 15 min. In a first series of experiments, we used NNA, an inhibitor of both neuronal NO synthase (nNOS) and endothelial NOS. Incubation of the slices in the presence of NNA prevented the stimulation-induced decrease in PSA IR (Fig. 5A,B). A similar result was obtained with 7-NI. To further confirm the role of NO in the reduction of PSA IR, we checked on halves separated from their control counterparts whether NO donors mimicked ST stimulation. As shown in Figure $5 B$, bath application of SNP or SNAP for 7.5 min reproduced the decrease in PSA IR seen after ST stimulation.

In NOS-containing neurons, glutamate-induced elevations of $\mathrm{Ca}^{2+}$ activate calmodulin and induce NO production by activating NOS (Snyder, 1992). Blockade of calmodulin by perfusion of slices with calmidazolium prevented the decrease in PSA IR induced by ST stimulation (Fig. 5C,D). NOS activation induces cGMP production in the hippocampus (East and Garthwaite, 1991). Thus, we asked whether production of cGMP via activation of soluble guanylyl cyclase was involved in the pathway 


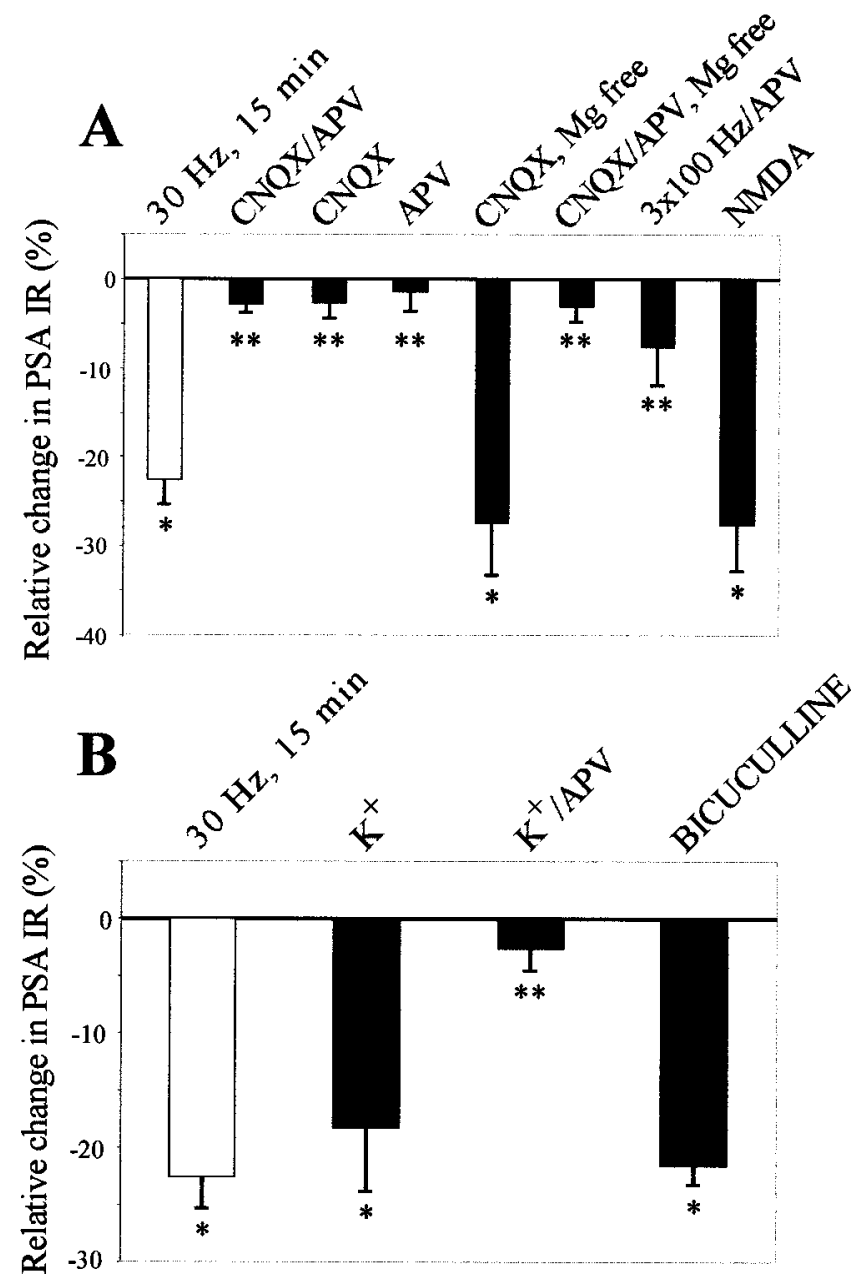

Figure 4. Regulation of PSA expression requires NMDA receptors. $A$, Glutamate receptor antagonists affect the percentage decrease of PSA IR after $30 \mathrm{~Hz}$ stimulation (15 min) or a high-frequency stimulation $(100 \mathrm{~Hz}$, $1 \mathrm{sec}, 5 \mathrm{~min})$. Preincubation of slices with both CNQX $(20 \mu \mathrm{M}, 10 \mathrm{~min})$ and APV $(50 \mu \mathrm{M}, 10 \mathrm{~min})$ together $(n=10)$ or separately $(n=10)$ inhibits the decrease in PSA IR. ST stimulation of slices perfused with CNQX $(n=5)$ in a magnesium-free ACSF (60 min), which removes the magnesium blockade of NMDA receptors, still induces a reduction of PSA IR but not in the presence of APV $(n=5)$. Bath application of NMDA (50 $\mu \mathrm{M}, 7.5 \mathrm{~min})(n=8)$ results in a similar PSA IR downregulation. Mean \pm SEM of the data. ${ }^{*} p<0.05$; Wilcoxon test; stimulated side versus contralateral side for a given condition. ${ }^{* *} p<0.05$; ANOVA; stimulated side $(30 \mathrm{~Hz}, 15 \mathrm{~min})$ versus stimulated and treated sides according to described experimental conditions. $B$, Addition of bicuculline $(25 \mu \mathrm{M}, 10 \mathrm{~min} ; n=$ 4) does not prevent the effects of ST stimulation. High-K ${ }^{+}$ACSF $(30 \mathrm{~mm}$, $7.5 \mathrm{~min} ; n=10$ ) results in a decrease of PSA IR that is sensitive to APV $(n=6)$. Mean \pm SEM of the data. ${ }^{*} p<0.05$; Wilcoxon test; stimulated side versus contralateral side for a given condition. ${ }^{* *} p<0.05$; ANOVA; stimulated side $(30 \mathrm{~Hz}, 15 \mathrm{~min})$ versus stimulated and treated sides according to described experimental conditions.

regulating PSA expression. Bath application of ODQ, a potent and selective inhibitor of this enzyme (Garthwaite et al., 1995), suppressed the effects of ST stimulation (Fig. $5 C, D$ ).

Because NO can act as a transcellular messenger, we chelated extracellular NO using PTIO (Fig. 5C,D) or carboxy-P TIO (data not shown), two membrane-impermeable NO scavengers (Ko and Kelly, 1999), to test whether NO diffusion was involved. We verified that, in the absence of stimulation, the PSA IR of PTIOtreated and untreated separated halves was not statistically different (data not shown). In the presence of the NO scavengers, the ST stimulation resulted in an increase in PSA IR. Furthermore, in all experiments, NO chelation caused instead an increase of PSA IR on the stimulated side (Fig. 5C,D). This result suggests that diffusible and intracellular NO may have opposing influences on the changes on PSA expression induced by ST stimulation. To further ascertain that NMDA receptor activation occurred upstream of NOS activation in the pathway, we tested the effects of NMDA addition in the presence of PTIO. For these experiments, DVCs were separated in two halves, one side being used as control. Here again, PSA-NCAM expression was upregulated in the NMDA-PTIO-treated half compared with the control hemislice (Fig. 5C,D).

This decrease in PSA IR is rapid and probably involves synaptic endocytosis of PSA, followed by its degradation. PAO and sucrose, two reagents reported to interfere with mechanisms involved in clathrin-dependent endocytosis (Frost and Lane, 1985; Heuser and Anderson, 1989), strongly reduced the decrease in PSA IR resulting from stimulation with the NO donor SNAP (Fig. 5E,F).

\section{The stimulation-induced PSA IR decrease is associated with NMDAR-dependent LTD}

To search for a possible link between the modulation of PSA expression by stimulation and plasticity occurring in the DVC, we recorded extracellular FPs in adult rat brainstem slices within the mNST. We showed (Fig. 6A,B) that a $100 \mathrm{~Hz}$ stimulation, which induced a PSA IR decrease, also induced LTD. The slope of field potentials was maximally reduced within 20 min after stimulation and remained depressed for the duration of the experiment. The $100 \mathrm{~Hz}$ stimulation did not change the amplitude of the presynaptic volley recorded extracellularly $(100 \pm 1 \%$ of control value; $n=6$ ), indicating that the stimulation excites the same number of fibers during the experiment (Fig. 6C). Twenty minutes after the $100 \mathrm{~Hz}$ stimulation, the average depression was $28 \pm 3 \%(n=8$; $p<0.001$; Mann-Whitney $U$ test). We further demonstrated that NMDAR activation was required during the induction by applying the NMDAR antagonist APV. Loading slices with APV blocked the ability to induce LTD $(9 \pm 5 \% ; n=5)($ Fig. $6 A)$ and in addition revealed a nonsignificant increase in the response. Therefore, NMDARs are likely to be involved in both triggering this form of synaptic plasticity and regulating PSA-NCAM expression, suggesting a link between LTD and PSA-NCAM endocytosis.

\section{The NMDA-NO pathway regulates PSA-NCAM expression in vivo}

We confirmed the physiological relevance of the activation of the NMDA-NO pathway after ST stimulation by showing that it was also functional in vivo. Cervical vagus nerve stimulation in anesthetized rats induced an ipsilateral reduction in PSA IR (Fig. 2). When the rats received systemic injections of MK-801 to block NMDA receptors or intraperitoneal injections of NNA to inhibit NOS activity, the stimulation-induced PSA IR decrease was significantly lower than it was in untreated animals (Fig. 7A,B).

\section{DISCUSSION}

The first finding of this study is that the expression of PSANCAM within the DVC of adult rats is dynamic and controlled by synaptic activity. Our study extends a previous report (Bonfanti et al., 1992) on mapping of PSA expression in adult rats by demonstrating a precise regional and cellular localization. Interestingly, PSA-NCAM expression is not observed in all NST subregions but only in the medial part of the NST, which is implicated in the 

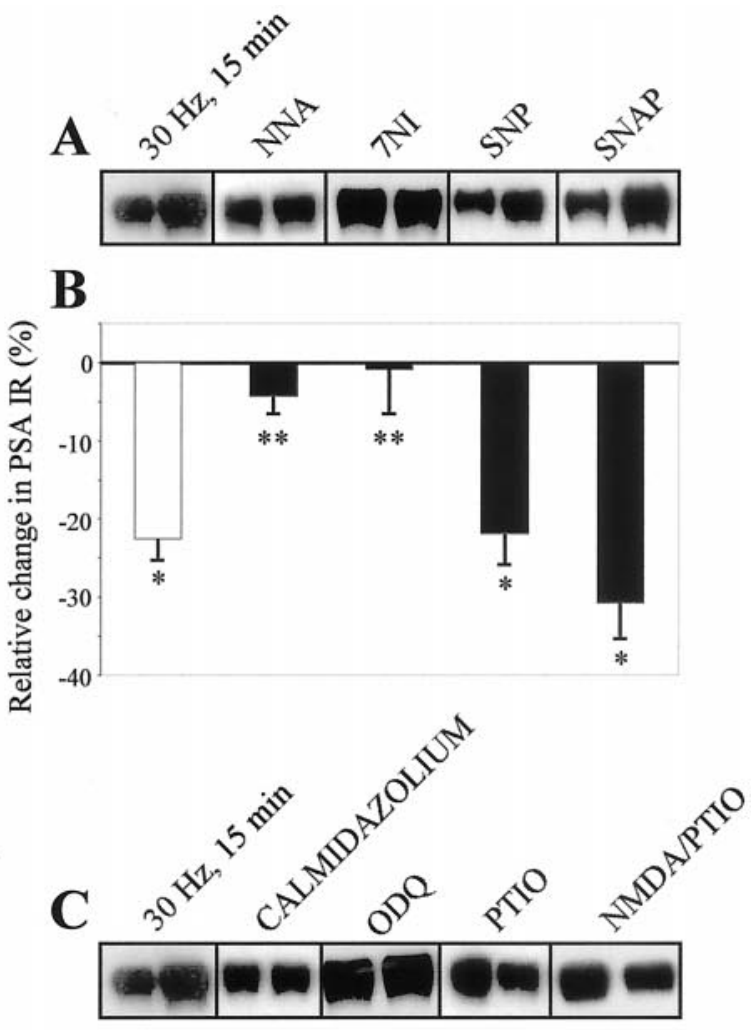

\section{D}
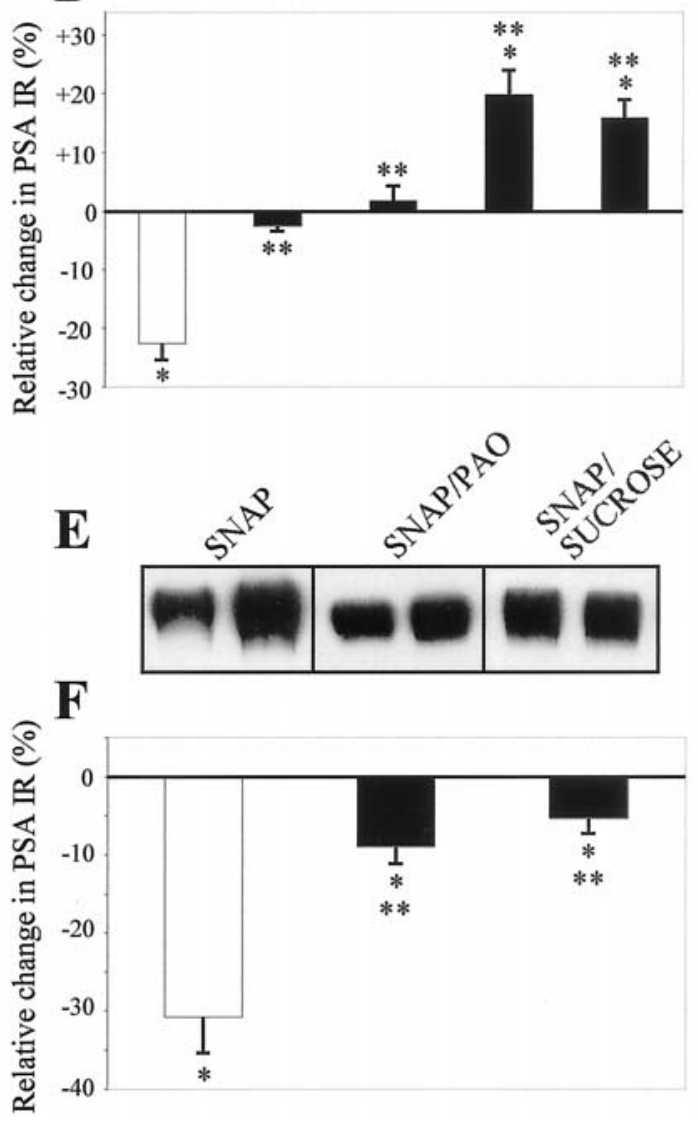

Figure 5. The nitric oxide-cGMP pathway regulates PSA expression. $A$, Typical Western blots probed with anti-PSA antibody. $B$, Preincubation of slices with NNA $(1 \mathrm{mM}, 60 \mathrm{~min} ; n=6)$ or 7 -NI $(100 \mu \mathrm{M}, 10 \mathrm{~min} ; n=6)$, two inhibitors of NOS, prevents stimulation-induced PSA IR decrease.
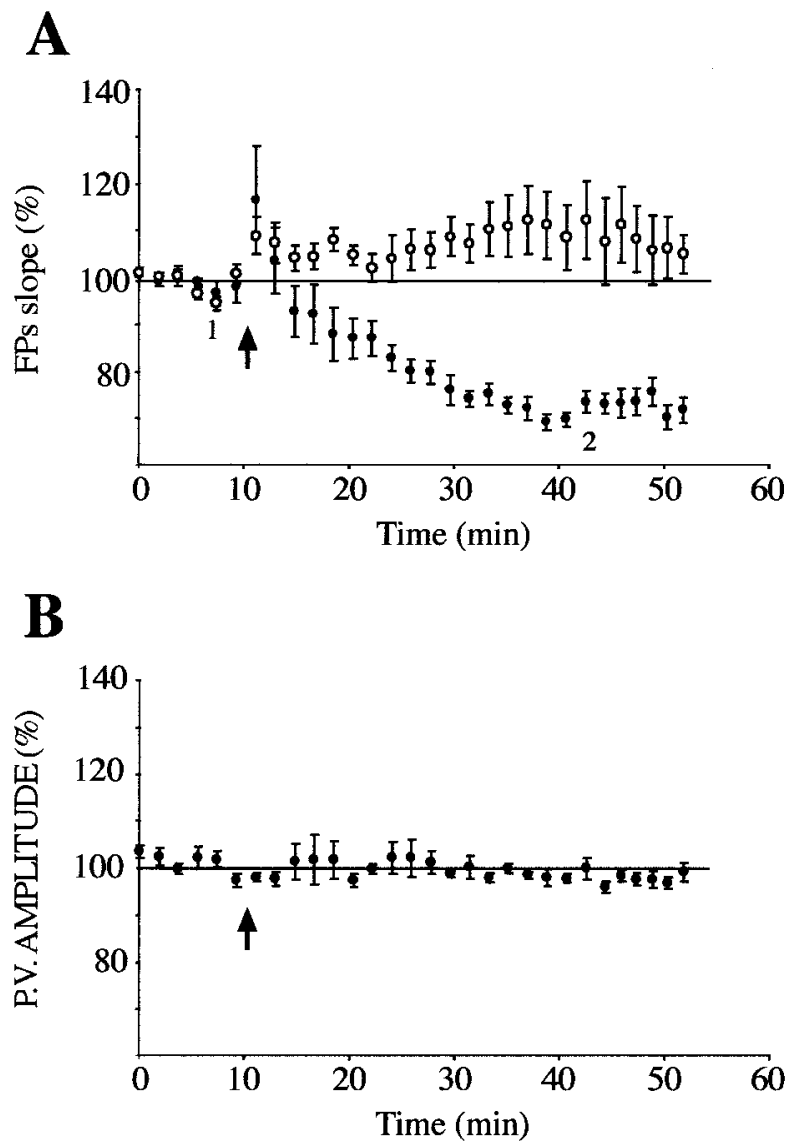

Figure 6. NMDAR-dependent LTD. A, Time course of changes in FP slope after $100 \mathrm{~Hz}$ stimulation. LTD is induced by $100 \mathrm{~Hz}$ stimulation $(\mathbf{0}$; $n=8)$, and $50 \mu \mathrm{M}$ APV blocks LTD $(\bigcirc ; n=5)$. The arrow indicates the time of stimulation. FPs are normalized to baseline set at $100 \% \pm$ SEM. $B$, No presynaptic changes could be detected. The amplitude of the presynaptic volley remained stable for the duration of the experiment.

regulation of visceral function. We show that, in the DVC, PSA is mainly associated with the NCAM $180 \mathrm{kDa}$ isoform, which is often expressed in postsynaptic membranes (Persohn et al., 1989; Persohn and Schachner, 1990). In agreement, PSA labeling was

Application of the two NO donors SNP $(100 \mu \mathrm{M}, 7.5 \mathrm{~min} ; n=9)$ and SNAP $(100 \mu \mathrm{M}, 7.5 \mathrm{~min} ; n=6)$ mimics the PSA IR decrease observed after ST stimulation. Mean \pm SEM of the data. ${ }^{*} p<0.05$; Wilcoxon test; stimulated side versus contralateral side for a given condition. ${ }^{* *} p<0.05$; ANOVA; stimulated side $(30 \mathrm{~Hz}, 15 \mathrm{~min})$ versus treated and stimulated sides according to described experimental conditions. $C$, Typical Western blot probed with anti-PSA antibody. $D$, Blockade of calmodulin with calmidazolium (200 nM, $20 \mathrm{~min} ; n=8$ ) or soluble guanylyl cyclase with ODQ $(10 \mu \mathrm{M}, 60 \mathrm{~min} ; n=6)$ inhibits the stimulation-induced PSA IR decrease. Chelation of diffusible NO with PTIO ( $3 \mu \mathrm{M}, 5 \mathrm{~min})$ results in an increase in PSA IR after ST $(n=9)$ or NMDA $(n=5)$ stimulation. Mean \pm SEM of the data. ${ }^{*} p<0.05$; Wilcoxon test; stimulated side versus contralateral side for a given condition. ${ }^{* *} p<0.05$; ANOVA; stimulated side $(30 \mathrm{~Hz}, 15 \mathrm{~min})$ versus stimulated and treated sides according to described experimental conditions. $E$, Typical Western blot probed with anti-PSA antibody. $F$, Incubation of slices with PAO (50 $\mu \mathrm{M}, 10 \mathrm{~min} ; n=$ $6)$ or sucrose $(0.45 \mathrm{M}, 20 \mathrm{~min} ; n=6)$ reduces PSA IR decrease after stimulation with the NO donor SNAP. Mean \pm SEM of the data. ${ }^{*} p<$ 0.05; Wilcoxon test; side treated with $\mathrm{NO}$ donor versus contralateral side for a given condition. ${ }^{* *} p<0.05$; ANOVA; NO donor-stimulated side versus corresponding sides treated according to described experimental conditions. 


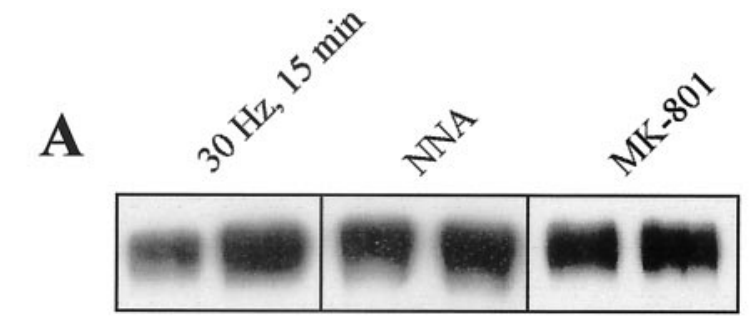

B

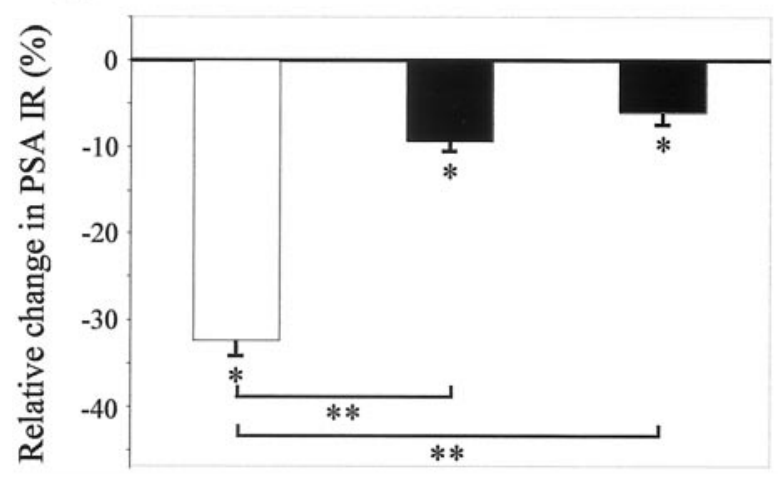

Figure 7. The NMDA-NO pathway regulates PSA expression in vivo. A, Typical Western blot. $B$, In anesthetized rats, systemic injection of MK$801(2 \mathrm{mg} / \mathrm{kg}, 5 \mathrm{~min}$ before stimulation; $n=9)$ or intraperitoneal injections of NNA (100 mg $/ \mathrm{kg}, 60 \mathrm{~min}$ before stimulation; $n=8)$ reduces the stimulation-induced PSA IR decrease. Mean \pm SEM of the data. ${ }^{*} p<$ 0.05 ; Wilcoxon test; stimulated versus contralateral side for a given condition. ${ }^{*} p<0.05$; ANOVA; stimulated side at the end of stimulation (15 min, $30 \mathrm{~Hz}$ ) from control rats versus corresponding stimulated sides from treated rats.

punctuate and closely apposed to synaptophysin- or GAP-43immunoreactive dots. However, this analysis did not allow us to determine the precise localization of PSA within the synapse. In the DVC, PSA did not colocalize with the astrocyte marker GFAP. This contrasts with its expression in axons and glia of the adult hypothalamo-hypophyseal system, a structure that undergoes profound structural remodeling after physiological stimulation (Theodosis et al., 1991). The PSA expression pattern in the DVC is reminiscent of that reported in the striatum and hippocampus. In the adult striatum, electron microscopy showed that PSA expression is confined to presynaptic and postsynaptic sites (Uryu et al., 1999). In the hippocampus, PSA-positive small boutons were found to make synaptic contacts with PSA-positive dendrite outgrowths (Seki and Arai, 1999). Such a localization strongly suggests that, in the DVC, PSA could contribute to structural remodeling of synapses.

Activity-dependent regulation of adhesion molecules has been reported previously in several systems (Fields and Itoh, 1996). The anatomy of the DVC, which allowed both access to slice preparations and the comparison of PSA IR levels in treated and control hemi-slices, was particularly suitable for experiments on the regulation of PSA expression. We provide here the first evidence for a rapid downregulation of PSA-NCAM levels induced by synaptic activation. Although in vivo stimulation probably activated both afferent and efferent fibers of the vagus nerve, it is unlikely that the decrease in PSA resulted from an antidromic activation of dorsal motor vagal neurons. Immunohistological observations showed that PSA IR was decreased throughout the DVC. In addition, in vitro stimulations of the ST (which contains only afferent fibers) gave similar results, and our pharmacological data strongly suggest that synaptic activation was crucial to induce changes in PSA expression. The modulation of PSA expression in the NST likely depends on ST stimulation, and those observed in the DMX may be attributable to the activation of local circuit interneurons and collaterals of second-order NST neurons, which establish local reflex arc with the DMX (Whitehead, 1988). Indeed, visceral afferent inputs have their first synaptic relay in the NST. There is some evidence that the first-order afferents make some monosynaptic contacts on the dorsally directed dendrites of the DMX (Rinaman et al., 1989).

Our evidence suggests that changes in PSA expression (1) resulted from increases in intracellular $\mathrm{Ca}^{2+},(2)$ required activation of NMDA receptors, and (3) involved the NO-cGMP signaling pathway. Downregulation of PSA was more pronounced when the duration of the $30 \mathrm{~Hz}$ stimulation or the number of high-frequency trains were increased. A $100 \mathrm{~Hz}$ frequency stimulation for $1 \mathrm{sec}$ was as efficient as $30 \mathrm{~Hz}$ frequency stimulation for $5 \mathrm{~min}$. High-frequency stimulation is likely to cause a rapid depolarization of the postsynaptic membrane, allowing a brief but intense $\mathrm{Ca}^{2+}$ influx.

The vast majority of vagus nerve sensory afferents liberate glutamate (Sykes et al., 1997). Accordingly, we observed that blockade of glutamate but not GABA receptors prevented the stimulation-induced PSA IR decrease. The effects of glutamate may depend on actions at different ionotropic receptors. Ionotropic receptor subtypes have been described within the DVC and can be activated by ST stimulation on brainstem slices (Tell and Jean, 1991; Travagli et al., 1991; Yen et al., 1999). In our model, activation of NMDA receptors is required to produce the observed PSA IR decrease. Finally, exogenous application of NMDA resulted in a decrease in PSA IR. Under physiological conditions, extracellular $\mathrm{Mg}^{2+}$ blocks the NMDA receptor channel at the resting membrane potential. High-frequency stimulation of presynaptic fibers should activate non-NMDA receptor channels sufficiently to depolarize the postsynaptic cell, remove the $\mathrm{Mg}^{2+}$ blockade, and permit $\mathrm{Ca}^{2+}$ entry via NMDA receptor channels (Nowak et al., 1984). Experiments with a high-K ${ }^{+}$saline further confirm the pivotal role of NMDA receptors. In this protocol, the decrease in PSA IR was entirely suppressed by APV, suggesting a negligible role in this effect for $\mathrm{Ca}^{2+}$ influx through voltage-dependent $\mathrm{Ca}^{2+}$ channels.

We examined the possible involvement of NO and cGMP, one of several signaling pathways that might be activated by a postsynaptic rise in $\mathrm{Ca}^{2+}$. Activation of NMDA receptors causes NO release in the cerebellar cortex and formation of cGMP through activation of NOS in hippocampus (East and Garthwaite, 1991). NOS is present in presynaptic and postsynaptic sites and cell bodies within the DVC of adult rats (Krowicki et al., 1997; Lin et al., 1998). In addition, NMDA-induced depolarization on DVC neurons is partly mediated by the activation of the NO-cGMP pathway (Travagli and Gillis, 1994). Our data clearly indicate that the decrease in PSA IR by afferent stimulation involves NO production and cGMP synthesis. Alteration of PSA expression was reproduced by directly adding NO donors into the perfusion medium. Interfering with NO production by blocking NOS activity with NNA and 7-NI prevented changes in PSA IR. Activation of nNOS requires activation of calmodulin by $\mathrm{Ca}^{2+}$ (Moore and Handy, 1997). Accordingly, inhibition of calmodulin suppressed the effects induced by ST stimulation. Finally, blockade of the soluble form of guanylyl cyclase by ODQ also suppressed the decrease in PSA IR. These conclusions are not limited to the slice preparation, because we confirmed in vivo that blockade of 
NMDA receptors by MK-801 and interfering with NO production with NNA prevented the decrease in PSA IR.

Interestingly, scavenging diffusible NO by PTIO or carboxyPTIO had an effect opposite to afferent stimulation or to NMDA application on PSA IR, whereas blocking NO synthesis simply prevented its occurrence. In the DVC, NO may act primarily as a transcellular messenger, inducing a strong endocytosis of PSA through production of cGMP. The increase in PSA IR upon extracellular application of NO scavengers may result from the postsynaptic action of NO and cGMP. Indeed, we observed that NOS or guanylyl cyclase inhibition prevented changes in PSA expression. A recent study on hippocampal synaptic transmission demonstrated that NO may serve as both a retrograde messenger and a postsynaptic intracellular signaling molecule (Ko and Kelly, 1999). However, our results also suggest that another mechanism not involving NO could participate in the regulation of PSA expression after ST stimulation.

PSA expression can be controlled at both transcriptional and post-transcriptional levels (Bruses et al., 1995; Bruses and Rutishauser, 1998), and differential regulation of PSA expression by activity is not unprecedented. During development, activity increases PSA expression in muscle but decreases it in nerve (Rutishauser and Landmesser, 1996). In addition, PSA can be externalized on the cell surface by differential delivery of intracellular stores in response to changes in intracellular $\mathrm{Ca}^{2+}$. Indeed, $\mathrm{Ca}^{2+}$ influx induces PSA-NCAM exocytosis in pancreatic cells (Kiss et al., 1994), whereas intracellular $\mathrm{Ca}^{2+}$ rise triggered by NMDA receptor activation have similar effects in oligodendrocyte precursors (Wang et al., 1996). Exocytosis and endocytosis are two complementary mechanisms suited to perform regulations in defined, restricted areas, such as synaptic sites. Here, we provide the first evidence for a rapid downregulation of PSA at central synapses. Both the kinetics of the changes in expression and their sensitivity to endocytosis blockers strongly support an involvement of PSA-NCAM endocytosis and rapid degradation of PSA. Our experimental conditions produced a strong and global decrease in PSA IR, which might obscure more subtle variations occurring at the synaptic level. Nevertheless, we have provided evidence that PSA expression in the DVC is synaptically regulated and that this event might be linked to LTD.

This rapid modulation of adhesion molecule expression at the cell surface is reminiscent of that reported for the NCAM homolog (apCAM) in Aplysia, fasciclin II in Drosophila (Schuster et al., 1996), and the mammalian neural cell adhesion molecule L1 (Kamiguchi et al., 1998).

PSA-NCAM, as well as NO, has an important role in synaptic plasticity in the mature brain. NO is required for the NMDAdependent form of synaptic plasticity in different brain regions (Lev-Ram et al., 1997; Calabresi et al., 1999). Removal of PSA from NCAM impairs long-term changes in synaptic efficacy in hippocampal organotypic slice cultures (Muller et al., 1996). Similar results were obtained by using antibodies raised against NCAM on acute hippocampal slices (Luthl et al., 1994). Our study has identified a functional link between NO production and PSA-NCAM regulation, integrating several observations on the involvement of NO and PSA-NCAM in synaptic plasticity. In Aplysia, serotonin-induced retrieval of apCAM from the presynaptic membrane, which should promote a less adhesive environment, is linked to LTP and synaptogenesis (Bailey et al., 1992; Mayford et al., 1992). If PSA has an anti-adhesive function (Rutishauser and Landmesser, 1996), then in our model it might facilitate morphological changes, whereas its endocytosis should increase adhesion and stabilize the synapses. Several experiments have failed to demonstrate LTP at excitatory synapses within the DVC (Glaum and Brooks, 1996). Recently, Zhou et al. (1997) presented instead direct evidence for LTD in 3- to 21-d-old NST neurons, dependent on activation of NMDA receptors, and a rise in intracellular $\mathrm{Ca}^{2+}$. Here, we also observed an NMDARdependent synaptic plasticity in the adult NST neurons with the same stimulation as the one used to induce a decrease in PSANCAM expression. Although other experiments are needed to demonstrate it, these results suggest that these two events may be linked.

In conclusion, our data provide strong evidence for a rapid modulation of PSA by synaptic activation in a mammalian model. The dynamic of PSA expression suggests that it plays a finely tuned role in the integration of afferent information within the DVC and so participates in the cellular mechanisms by which this structure contributes to the homeostatic regulation of visceral function.

\section{REFERENCES}

Bailey CH, Chen M, Keller F, Kandel ER (1992) Serotonin-mediated endocytosis of apCAM: an early step of learning-related synaptic growth in Aplysia. Science 256:645-649.

Barraco RC (1994) Nucleus of the solitary tract. Boca Raton, FL: CRC.

Bonfanti L, Olive S, Poulain DA, Theodosis DT (1992) Mapping of the distribution of polysialylated neural cell adhesion molecule throughout the central nervous system of the adult rat: an immunohistochemical study. Neuroscience 49:419-436.

Bruses JL, Rutishauser U (1998) Regulation of neural cell adhesion molecule polysialylation: evidence for nontranscriptional control and sensitivity to an intracellular pool of calcium. J Cell Biol 140:1177-1186.

Bruses JL, Oka S, Rutishauser U (1995) NCAM-associated polysialic acid on ciliary ganglion neurons is regulated by polysialytransferase levels and interaction with muscle. J Neurosci 15:8310-8319.

Calabresi P, Gubellini P, Centonze D, Sancesario G, Morello M, Giorgi M, Pisani A, Bernardi G (1999) A critical role of the nitric oxide/ cGMP pathway in corticostriatal long-term depression. J Neurosci 19:2489-2499.

Cremer H, Chazal G, Carleton A, Goridis C, Vincent JD, Lledo PM (1998) Long-term but not short-term plasticity at mossy fiber synapses is impaired in neural cell adhesion molecule-deficient mice. Proc Natl Acad Sci USA 95:13242-13247.

East SJ, Garthwaite J (1991) NMDA receptor activation in rat hippocampus induces cyclic GMP formation through the L-arginine-nitric oxide pathway. Neurosci Lett 123:17-19.

Fields RD, Itoh K (1996) Neural cell adhesion molecules in activitydependent development and synaptic plasticity. Trends Neurosci 19:473-480.

Frost SC, Lane MD (1985) Evidence for the involvement of vicinal sulfhydryl groups in insulin-activated hexose transport by 3T3-L1 adipocytes. J Biol Chem 260:2646-2652.

Garthwaite J, Southam E, Boulton CL, Nielsen EB, Schmidt K, Mayer B (1995) Potent and selective inhibition of nitric oxide-sensitive guanylyl cyclase by $1 \mathrm{H}-[1,2,4]$ oxadiazolo[4,3-a]quinoxalin-1-one. Mol Pharmacol 48:184-188.

Glaum SR, Brooks PA (1996) Tetanus-induced sustained potentiation of monosynaptic inhibitory transmission in the rat medulla: evidence for a presynaptic locus. J Neurophysiol 76:30-38.

Heuser JE, Anderson RG (1989) Hypertonic media inhibit receptormediated endocytosis by blocking clathrin-coated pit formation. J Cell Biol 108:389-400.

Jean A (1991) The nucleus tractus solitarius: neuroanatomic, neurochemical and functional aspects (in French). Arch Int Physiol Biochim Biophys 99:A3-A52.

Kamiguchi H, Long KE, Pendergast M, Schaefer AW, Rapoport I, Kirchhausen T, Lemmon V (1998) The neural cell adhesion molecule L1 interacts with the AP-2 adaptor and is endocytosed via the clathrinmediated pathway. J Neurosci 18:5311-5321.

Kiss JZ, Rougon G (1997) Cell biology of polysialic acid. Curr Opin Neurobiol 7:640-646.

Kiss JZ, Wang C, Olive S, Rougon G, Lang J, Baetens D, Harry D, Pralong WF (1994) Activity-dependent mobilization of the adhesion molecule polysialic NCAM to the cell surface of neurons and endocrine cells. EMBO J 13:5284-5292.

Ko GY, Kelly PT (1999) Nitric oxide acts as a postsynaptic signaling molecule in calcium/calmodulin-induced synaptic potentiation in hippocampal CA1 pyramidal neurons. J Neurosci 19:6784-6794. 
Krowicki ZK, Sharkey KA, Serron SC, Nathan NA, Hornby PJ (1997) Distribution of nitric oxide synthase in rat dorsal vagal complex and effects of microinjection of nitric oxide compounds upon gastric motor function. J Comp Neurol 377:49-69.

Kruger L, Bendotti C, Rivolta R, Samanin R (1993) Distribution of GAP-43 mRNA in the adult rat brain. J Comp Neurol 333:417-434.

Lev-Ram V, Jiang T, Wood J, Lawrence DS, Tsien RY (1997) Synergies and coincidence requirements between NO, cGMP, and Ca2 + in the induction of cerebellar long-term depression. Neuron 18:1025-1038.

Lin LH, Cassell MD, Sandra A, Talman WT (1998) Direct evidence for nitric oxide synthase in vagal afferents to the nucleus tractus solitarii. Neuroscience 84:549-558.

Luthl A, Laurent JP, Figurov A, Muller D, Schachner M (1994) Hippocampal long-term potentiation and neural cell adhesion molecules L1 and NCAM. Nature 372:777-779.

Mayford M, Barzilai A, Keller F, Schacher S, Kandel ER (1992) Modulation of an NCAM-related adhesion molecule with long-term synaptic plasticity in Aplysia. Science 256:638-644.

Miles R (1986) Frequency dependence of synaptic transmission in nucleus of the solitary tract in vitro. J Neurophysiol 55:1076-1090.

Moore PK, Handy RL (1997) Selective inhibitors of neuronal nitric oxide synthase-is no NOS really good NOS for the nervous system? Trends Pharmacol Sci 18:204-211.

Muller D, Wang C, Skibo G, Toni N, Cremer H, Calaora V, Rougon G, Kiss JZ (1996) PSA-NCAM is required for activity-induced synaptic plasticity. Neuron 17:413-422.

Nowak L, Bregestovski P, Ascher P, Herbet A, Prochiantz A (1984) Magnesium gates glutamate-activated channels in mouse central neurones. Nature 307:462-465.

Persohn E, Schachner M (1990) Immunohistological localization of the neural adhesion molecules L1 and N-CAM in the developing hippocampus of the mouse. J Neurocytol 19:807-819.

Persohn E, Pollerberg GE, Schachner M (1989) Immunoelectronmicroscopic localization of the $180 \mathrm{kD}$ component of the neural cell adhesion molecule N-CAM in postsynaptic membranes. J Comp Neurol 288:92-100.

Rinaman L, Card JP, Schwaber JS, Miselis RR (1989) Ultrastructural demonstration of a gastric monosynaptic vagal circuit in the nucleus of the solitary tract in rat. J Neurosci 9:1985-1996.

Rougon G, Marshak DR (1986) Structural and immunological characterization of the amino-terminal domain of mammalian neural cell adhesion molecules. J Biol Chem 261:3396-3401.

Rougon G, Dubois C, Buckley N, Magnani JL, Zollinger W (1986) A monoclonal antibody against meningococcus group $\mathrm{B}$ polysaccharides distinguishes embryonic from adult N-CAM. J Cell Biol 103:2429-2437.

Rutishauser U, Landmesser L (1996) Polysialic acid in the vertebrate nervous system: a promoter of plasticity in cell-cell interactions. Trends Neurosci 19:422-427.

Saha S, Batten TF, McWilliam PN (1995) Glutamate, gammaaminobutyric acid and tachykinin-immunoreactive synapses in the cat nucleus tractus solitarii. J Neurocytol 24:55-74.

Schaffar N, Rao H, Kessler JP, Jean A (1997) Immunohistochemical detection of glutamate in rat vagal sensory neurons. Brain Res 778:302-308.

Schuster CM, Davis GW, Fetter RD, Goodman CS (1996) Genetic dissection of structural and functional components of synaptic plasticity. II. Fasciclin II controls presynaptic structural plasticity. Neuron 17:655-667.

Seki T, Arai Y (1993) Distribution and possible roles of the highly polysialylated neural cell adhesion molecule (NCAM-H) in the developing and adult central nervous system. Neurosci Res 17:265-290.

Seki T, Arai Y (1999) Different polysialic acid-neural cell adhesion molecule expression patterns in distinct types of mossy fiber boutons in the adult hippocampus. J Comp Neurol 410:115-125.

Snyder SH (1992) Nitric oxide and neurons. Curr Opin Neurobiol 2:323-327.

Sykes RM, Spyer KM, Izzo PN (1997) Demonstration of glutamate immunoreactivity in vagal sensory afferents in the nucleus tractus solitarius of the rat. Brain Res 762:1-11.

Tell F, Jean A (1991) Bursting discharges evoked in vitro, by solitary tract stimulation or application of $N$-methyl-D-aspartate, in neurons of the rat nucleus tractus solitarii. Neurosci Lett 124:221-224.

Theodosis DT, Rougon G, Poulain DA (1991) Retention of embryonic features by an adult neuronal system capable of plasticity: polysialylated neural cell adhesion molecule in the hypothalamo-neurohypophysial system. Proc Natl Acad Sci USA 88:5494-5498.

Travagli RA, Gillis RA (1994) Nitric oxide-mediated excitatory effect on neurons of dorsal motor nucleus of vagus. Am J Physiol 266:G154-G160.

Travagli RA, Gillis RA, Rossiter CD, Vicini S (1991) Glutamate and GABA-mediated synaptic currents in neurons of the rat dorsal motor nucleus of the vagus. Am J Physiol 260:G531-G536.

Uryu K, Butler AK, Chesselet MF (1999) Synaptogenesis and ultrastructural localization of the polysialylated neural cell adhesion molecule in the developing striatum. J Comp Neurol 405:216-232.

Vincent A, Tell F (1997) Postnatal changes in electrophysiological properties of rat nucleus tractus solitarii neurons. Eur J Neurosci 9:1612-1624.

Wang C, Pralong WF, Schulz MF, Rougon G, Aubry JM, Pagliusi S, Robert A, Kiss JZ (1996) Functional $N$-methyl-D-aspartate receptors in O-2A glial precursor cells: a critical role in regulating polysialic acid-neural cell adhesion molecule expression and cell migration. J Cell Biol 135:1565-1581.

Whitehead MC (1988) Neuronal architecture of the nucleus of the solitary tract in the hamster. J Comp Neurol 276:547-572.

Yen JC, Chan JY, Chan SH (1999) Differential roles of NMDA and non-NMDA receptors in synaptic responses of neurons in nucleus tractus solitarii of the rat. J Neurophysiol 81:3034-3043.

Zhou Z, Poon CS (2000) Field potential analysis of synaptic transmission in spiking neurons in a sparse and irregular neuronal structure in vitro. J Neurosci Methods 94:193-203.

Zhou Z, Champagnat J, Poon CS (1997) Phasic and long-term depression in brainstem nucleus tractus solitarius neurons: differing roles of AMPA receptor desensitization. J Neurosci 17:5349-5356. 